\title{
Tetracene Derivatives as Potential Red Emitters for Organic LEDs
}

\author{
Susan A. Odom, Sean R. Parkin, John E. Anthony* \\ Department of Chemistry, University of Kentucky \\ Lexington, KY 40506-0055
}

Supplementary Information

\begin{abstract}
All materials and solvents were obtained from Aldrich Chemical Co. (Milwaukee, WI) or Acros Organics (Pittsburgh, PA) and were used without further purification unless other wise noted. Commercially obtained alkynes were purchased from GFS Chemicals (Powell, $\mathrm{OH}$ ). Moisture sensitive reactions were carried out in oven-dried glassware cooled under dry nitrogen. For solvents used in moisture sensitive reactions, diethylether was purified by passage through activated alumina, and dry THF was obtained from EM Science (DriSolv). All ${ }^{1} \mathrm{H}$ NMR spectra were obtained at $399.727 \mathrm{MHz}$, and all ${ }^{13} \mathrm{C}$ NMR spectra were recorded at $100.511 \mathrm{MHz}$ using a Varian Inova $400 \mathrm{MHz}$ NMR. ${ }^{1} \mathrm{H}$ NMR and ${ }^{13} \mathrm{C}$ NMR data are reported in parts per million $(\square)$ downfield from tetramethylsilane. Melting points were recorded using differential scanning calorimetry using a TA Instruments Differential Scanning Calorimeter model number DSC 2920. UV-Vis absorbance spectra were obtained using a Shimadzu UV-Vis recording spectrophotometer model UV-2501PC. Solution photoluminescence spectra and solidstate electroluminescence spectra were recorded using a Jobin Yvon-Spex Fluorolog-3 Fluorimeter model number FL3-11. Fluorescence Quantum Efficiencies were recorded using HPLC grade hexanes as the solvent, and the standard used was rubrene in hexanes, following a literature procedure. ${ }^{1}$ Thin layer chromatography was performed on MERCK Silica Gel 60 think layer plates. Silica gel chromatography was performed on Sorbent Technologies brand silica gel (32-63 $\square \mathrm{m}$, Standard Grade). Elemental analysis was performed by Complete Analysis Laboratories Inc., Parsippany, New Jersey. The evaporation system used to fabricate organic light-emitting diodes (OLEDs) was a modified system purchased from Cressington. Mass spectra for MALDI time-of-flight data were obtained using a Kratos Kompact SEQ spectrometer. Mass spectra for EI were obtained using a Finnigan Polaris Q using an ion trap mass analyzer.
\end{abstract}




\section{Synthetic Procedures and Characterization}<smiles></smiles><smiles>[R]C#Cc1c2ccccc2c(OC)c2c(OC)c3ccccc3c(OC)c12</smiles>

General Procedure for the Synthesis of Tetracene Derivatives: One equivalent of the appropriate alkyne was dissolved in $20 \mathrm{~mL}$ of anhydrous diethyl ether in a $250 \mathrm{~mL}$ ovendried round bottom flask under nitrogen atmosphere. 0.9 equivalents of $n$-butyl lithium (2.5 $\mathrm{M}$ solution in hexanes) were added by syringe and the solution was stirred at room temperature for 30 minutes. Then 0.33 equivalents of 5,12-tetracene quinone (1) or 5,12dimethoxy-6,13-tetracene quinone (2) were added followed by $20 \mathrm{~mL}$ of anhydrous diethyl ether, and the reaction was allowed to stir at room temperature overnight. To the solution was then added $100 \mathrm{~mL}$ of saturated $\mathrm{SnCl}_{2}$ in $10 \%$ aqueous $\mathrm{HCl}$ solution and THF was added to increased miscibility of the aqueous and organic layers. Upon addition, the flask was stirred under nitrogen for 30 minutes, and the reaction was monitored by TLC. Upon completion, the mixture was extracted with dichloromethane or hexanes and was washed with water. The solution was dried with $\mathrm{MgSO}_{4}$ and was flushed through a cake of silica gel and was concentrated by rotary evaporation. The product was further purified by flash column chromatography with silica gel using either hexanes, 9:1 hexanes:dichloromethane, or 1:1 hexanes:dichloromethane, yielding a solid.<smiles>O=C1c2ccccc2C(=O)c2cc3ccccc3cc21</smiles>

(1) 5,12-tetracene quinone. To an $500 \mathrm{~mL}$ round bottom flask under nitrogen atmosphere was added 1,4-napthoquinone ( $1 \mathrm{~g}, 6.2 \mathrm{mmol})$, tetrabromo- $o$-xylene $(10 \mathrm{~g}, 23.9 \mathrm{mmol})$, sodium iodide $(23 \mathrm{~g}, 163 \mathrm{mmol})$, calcium carbonate $(5 \mathrm{~g}, 50 \mathrm{mmol})$, and $N, N$ dimethylformamide $(75 \mathrm{~mL})$. The mixture was sparged with nitrogen at room temperature for 30 minutes. The reaction was then brought to $55^{\circ} \mathrm{C}$ to stir for two days. The mixture was poured into $200 \mathrm{~mL}$ of water, and the yellow solid was filtered and washed with acetone. To remove calcium carbonate from the product, the solid was recrystallized with acetone. The product, a yellow solid, was obtained in $65 \%$ yield. The spectra data are consistent of a previous reported synthesis of this compound. ${ }^{2}$<smiles>COc1c2c(c(OC)c3ccccc13)C(=O)c1ccccc1C2=O</smiles>

(2) 5,12-dimethoxy-6,13-tetracene quinone. 5,12-dihydroxy-6,13-tetracenequinone (1 g, $3.4 \mathrm{mmol})$, acetone $(500 \mathrm{~mL})$, and dioxane $(150 \mathrm{~mL})$ were combined in round bottom 
flask, and dimethyl sulfate $(9.4 \mathrm{~mL}, 57 \mathrm{mmol})$ and anhydrous potassium carbonate $(5 \mathrm{~g}$, $39.4 \mathrm{mmol}$ ) were added. The solvents were sparged with nitrogen for 30 minutes and then heated to reflux under nitrogen for two days whereupon a yellow precipitate formed. The reaction mixture was poured into ice water to complete precipitation of the product, which was filtered and recrystallized from acetone. The product, a yellow solid, was isolated in $85 \%$ yield and had spectral data consistent with material reported in the literature. $^{3}$

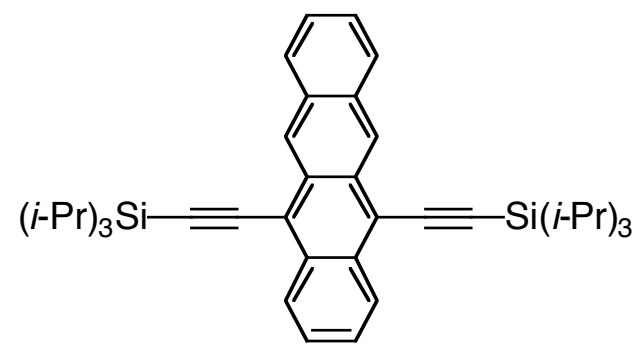

(3) 5,12-bis(triisopropylsilylethynyl)tetracene was prepared following the general tetracene procedure using triisopropylsilyl acetylene and $\mathbf{1}$. The product was recrystallized from acetone. ${ }^{1} \mathrm{H} \mathrm{NMR}\left(\mathrm{CDCl}_{3}\right) \square 1.35(\mathrm{~s}, 42 \mathrm{H}), 7.48(\mathrm{dd}, 2 \mathrm{H}, J=2.8$, $6.4 \mathrm{~Hz}), 7.56(\mathrm{dd}, 2 \mathrm{H}, J=2.8,6.8 \mathrm{~Hz}), 8.04(\mathrm{dd}, 2 \mathrm{H}, J=2.8,6.8 \mathrm{~Hz}), 8.65(\mathrm{dd}, 2 \mathrm{H}, J=$ 2.8, $6.4 \mathrm{~Hz}), 9.34$ (s, $2 \mathrm{H}) .{ }^{13} \mathrm{C} \mathrm{NMR}\left(\mathrm{CDCl}_{3}\right) \square 11.81,19.17,104.15,106.06,118.81$, 126.21, 126.52, 126.89, 127.62, 128.79, 130.56, 132.38, 132.83. MS (m/z, EI) 588 (M+, $100 \%), 545\left(\mathrm{M}+-i\right.$-Pr). Anal Calcd for $\mathrm{C}_{42} \mathrm{H}_{36} \mathrm{Si}_{2}: \mathrm{C}, 81.56 ; \mathrm{H}, 8.89$. Found $\mathrm{C}, 81.61 ; \mathrm{H}$, 9.15. Melting point: $130{ }^{\circ} \mathrm{C}$. Fluorescence Quantum Efficiency: 0.79. Yield: $98 \%$. UVVis (hexanes) $\square_{\mathrm{nm}}(\log \square: 291$ (5.27), 316 (4.18), 332 (4.07), 351 (3.62), 466 (3.76), 498 (4.23), 535 (4.42).

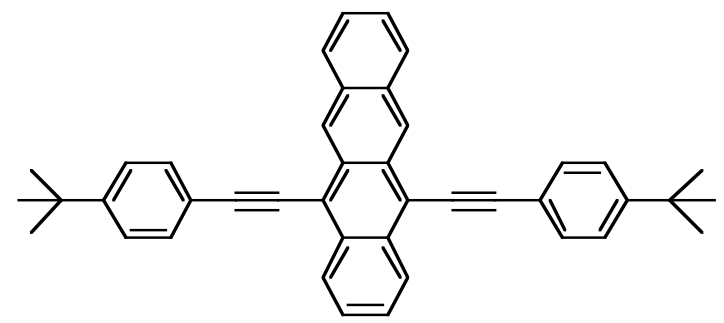

(4) 5,12-bis(4-t-butylphenylethynyl)tetracene was prepared using the general tetracene procedure using 4-t-butylphenylacetylene and $\mathbf{1}$. The material was purified by chromatography on silica gel (hexanes eluent). ${ }^{1} \mathrm{H} \mathrm{NMR}\left(\mathrm{CDCl}_{3}\right) \square 1.42(\mathrm{~s}, 18 \mathrm{H}), 7.48$ $(\mathrm{dd}, 2 \mathrm{H}, J=2.8,6.4 \mathrm{~Hz}), 7.54(\mathrm{~d}, 4 \mathrm{H}, J=6.8 \mathrm{~Hz}), 7.58(\mathrm{dd}, 2 \mathrm{H}, J=3.2,6.8 \mathrm{~Hz}), 7.79$ $(\mathrm{d}, 4 \mathrm{H}, J=6.8 \mathrm{~Hz}), 8.12(\mathrm{dd}, 2 \mathrm{H}, J=3.2,6.4 \mathrm{~Hz}), 8.70(\mathrm{dd}, 2 \mathrm{H}, J=3.2,6.8 \mathrm{~Hz}), 9.32$ $(\mathrm{s}, 2 \mathrm{H}) .{ }^{13} \mathrm{C} \mathrm{NMR}\left(\mathrm{CDCl}_{3}\right) \square 31.46,35.18,86.79,103.64,118.56,120.78,125.85$, $126.13,126.31,126.71,127.65,128.80,130.17,131.72,132.31,132.45,152.35$. MS $(\mathrm{m} / \mathrm{z}, \mathrm{EI}) 540(\mathrm{M}+, 100 \%), 525\left(\mathrm{M}+-\mathrm{CH}_{3}\right)$. Anal Calcd for $\mathrm{C}_{42} \mathrm{H}_{36}: \mathrm{C}, 93.29 ; \mathrm{H}, 6.71$. Found C, 93.15; H, 6.62. Melting point: $132{ }^{\circ} \mathrm{C}$. Fluorescence Quantum Efficiency: 0.81. Yield: $98 \%$. UV-Vis (hexanes) $\square_{\mathrm{nm}}(\log \square: 290$ (5.44), 357 (4.42), 485 (3.87), 514 (4.24), 556 (4.38). 


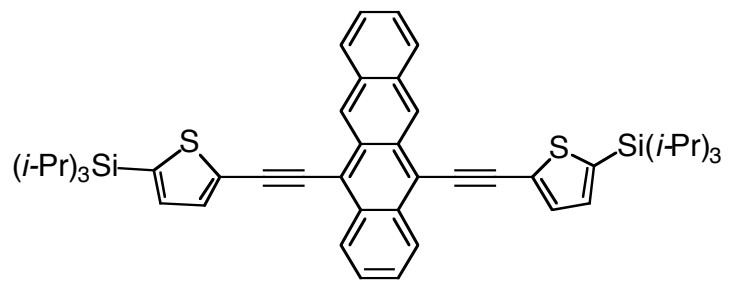

(5) 5,12-bis(5-triisopropylsilylthienylethynyl)tetracene was prepared using the general tetracene procedure using 5-triisopropylsilyl-2-ethynyl thiophene and 1. ${ }^{1} \mathrm{H}$ NMR $\left(\mathrm{CDCl}_{3}\right) \square 1.19(\mathrm{~d}, 18 \mathrm{H}, J=7.2 \mathrm{~Hz}), 1.44$ (septet, $\left.6 \mathrm{H}, J=7.2 \mathrm{~Hz}\right), 7.31$ (d, $2 \mathrm{H}, J=3.6$ $\mathrm{Hz}), 7.49(\mathrm{dd}, 2 \mathrm{H}, J=2.8,6.8 \mathrm{~Hz}), 7.58(\mathrm{dd}, 2 \mathrm{H}, J=3.2,6.8 \mathrm{~Hz}), 7.66(\mathrm{~d}, 2 \mathrm{H}, J=3.2$ $\mathrm{Hz}), 8.13(\mathrm{dd}, 2 \mathrm{H}, J=3.2,6.4 \mathrm{~Hz}), 8.62(\mathrm{dd}, 2 \mathrm{H}, J=3.2,6.8 \mathrm{~Hz}), 9.22(\mathrm{~s}, 2 \mathrm{H}) .{ }^{13} \mathrm{C}$ NMR $\left(\mathrm{CDCl}_{3}\right) \square 12.06,18.81,92.45,96.84,118.39,126.24,126.93,127.60,128.38$, 128.83, 129.70, 129.87, 132.29, 132.39, 133.28, 135.96, 139.12. MS (m/z, EI) $752(\mathrm{M}+)$, 710 (100\%, M+ - $i$-Pr). Anal Calcd for $\mathrm{C}_{48} \mathrm{H}_{56} \mathrm{~S}_{2} \mathrm{Si}_{2} \mathrm{O}_{2}$ (endoperoxide formed during shipment): C, 73.41; H, 7.18. Found C, 74.73; H, 7.28. Melting point: $187^{\circ} \mathrm{C}$.

Fluorescence Quantum Efficiency: 0.69. Yield: 55\%. UV-Vis (hexanes) $\square_{\mathrm{nm}}(\log \square: 280$ (5.33), 376 (4.36), 470 (3.62), 531 (4.28), 570 (4.41). Structure further confirmed by Xray crystallographic analysis:
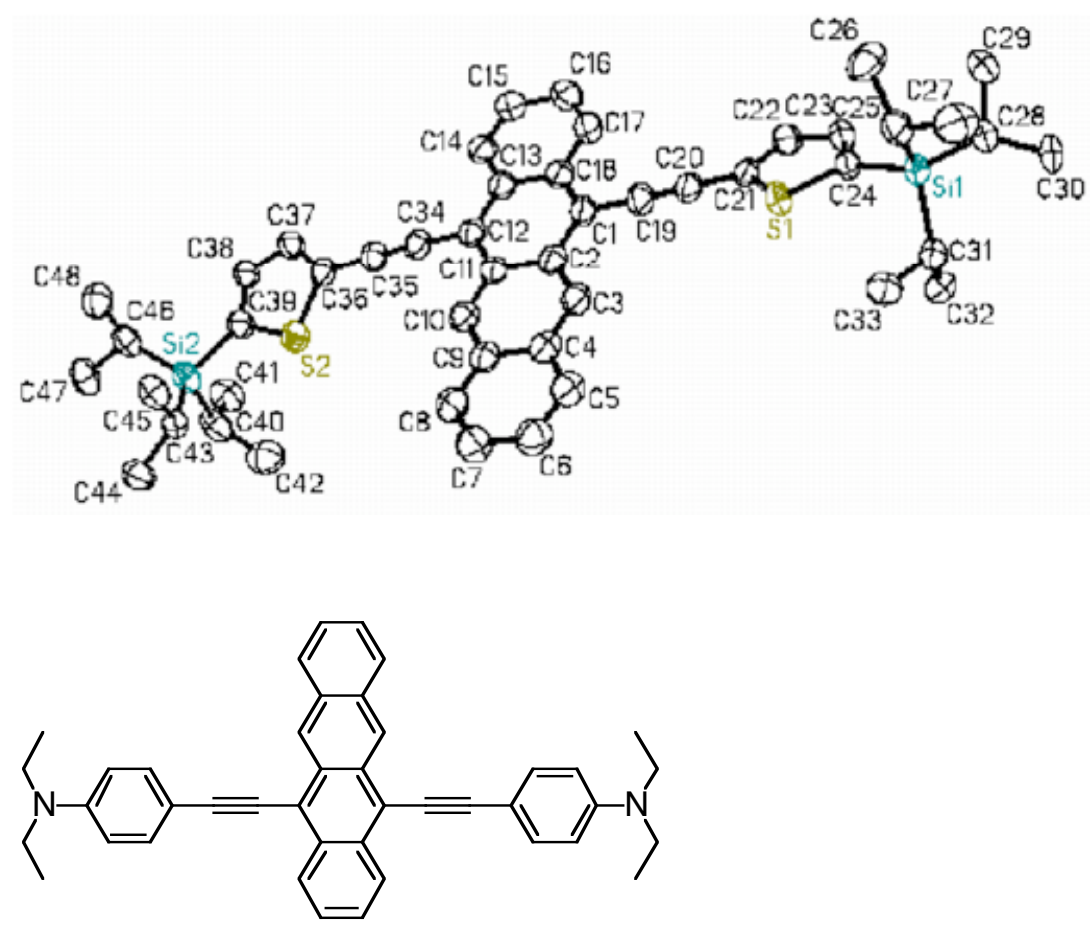

(6) 5,12-bis(4-(N,N-diethylamino)phenylethynyl)tetracene was prepared by the general procedure using 4-(diethylamino)phenylacetylene and $\mathbf{1}$. The product was purified by recrystallization from 2-butanone. ${ }^{1} \mathrm{H} \mathrm{NMR}\left(\mathrm{CDCl}_{3}\right) \square 1.26(\mathrm{t}, 12 \mathrm{H}, J=6.4 \mathrm{~Hz}), 3.47$ (q, $8 \mathrm{H}, J=6.4 \mathrm{~Hz}), 6.76(\mathrm{~d}, 4 \mathrm{H}, J=8.4 \mathrm{~Hz}), 7.46(\mathrm{dd}, 2 \mathrm{H}, J=3.2,6.8 \mathrm{~Hz}), 7.55(\mathrm{dd}, 2 \mathrm{H}$, $J=3.2,6.8 \mathrm{~Hz}), 7.74(\mathrm{~d}, 4 \mathrm{H}, J=8.4 \mathrm{~Hz}), 8.11(\mathrm{dd}, 2 \mathrm{H}, J=3.2,6.4 \mathrm{~Hz}), 8.70(\mathrm{dd}, 2 \mathrm{H}, J$ $=3.2,6.8 \mathrm{~Hz}), 9.32(\mathrm{~s}, 2 \mathrm{H}) .{ }^{13} \mathrm{C} \mathrm{NMR}\left(\mathrm{CDCl}_{3}\right) \square 12.81,44.67,85.71,105.20,109.50$, $111.59,118.50,125.82,126.29,126.40,127.83,130.16,132.13,133.36,148.04$. MS $(\mathrm{m} / \mathrm{z}, \mathrm{MALDI})=570(\mathrm{M}+)$. Anal Calcd for $\mathrm{C}_{42} \mathrm{H}_{36} \mathrm{~N}_{2}$ : C. 88.69; H, 6.37; N, 4.92. Found 
C, 87.99; H, 6.58; N, 5.15. Melting point: $250^{\circ} \mathrm{C}$ (dec.). Fluorescence Quantum Efficiency: 0.10. Yield: 49\%. UV-Vis (hexanes) $\square_{\mathrm{nm}}$ (log \): 277 (5.96), 352 (4.37), 380 (4.42), 556 (4.51), 595 (4.61).

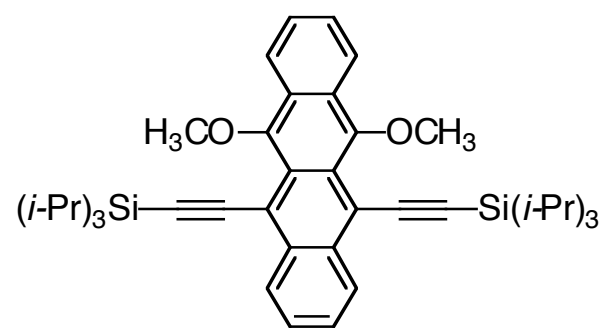

(7) 5,12-dimethoxy-6,11-bis(triisopropylsilylethynyl)tetracene was prepared using the general tetracene procedure with triisopropylsilyl acetylene and $\mathbf{2}$. The product was purified by recrystallization from acetone, yielding material suitable for $\mathrm{X}$-ray analysis. ${ }^{1} \mathrm{H} \mathrm{NMR}\left(\mathrm{CDCl}_{3}\right) \square 1.32$ (br. s, $42 \mathrm{H}$ ), 4.07 (s, $\left.6 \mathrm{H}\right), 7.48$ (dd, $\left.2 \mathrm{H}, J=3.2,6.8\right), 7.55$ (dd, $2 \mathrm{H}, J=3.2,6.8 \mathrm{~Hz}), 8.33(\mathrm{dd}, 2 \mathrm{H}, J=3.2,6.8 \mathrm{~Hz}), 8.90(\mathrm{dd}, 2 \mathrm{H}, J=3.2,6.8 \mathrm{~Hz}) .{ }^{13} \mathrm{C}$ $\operatorname{NMR}\left(\mathrm{CDCl}_{3}\right) \square 12.03,19.12,64.05,106.02,106.80,115.81,123.30,124.95,125.61$, 126.08, 126.99, 127.92, 134.29, 149.94. MS (m/z, EI) 648 (100\%, M+), 633 (80\%, M+ Me). Anal Calcd for $\mathrm{C}_{42} \mathrm{H}_{56} \mathrm{O}_{2} \mathrm{Si}_{2}$ : C, 77.72; H, 8.69. Found C, 77.79; H, 9.01. Melting point: $124^{\circ} \mathrm{C}$. Fluorescence Quantum Efficiency: 0.19. Yield: 88\%. UV-Vis (hexanes) $\square_{\mathrm{m}}(\log$ ฤ: 300 (5.29), 329 (4.12), 347 (3.95), 380 (3.62), 501 (3.81), 538 (4.19), 580 (4.32).

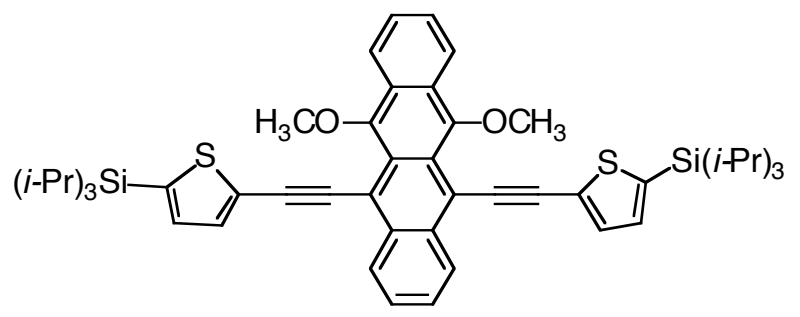

(8) 5,12-dimethoxy-6,11-bis(5-triisopropylsilylthienylethynyl)tetracene was prepared using the general tetracene procedure with 5-triisopropylsilyl-2-ethynyl thiophene and $\mathbf{2}$. The product was purified by repeated chromatography on silica gel (hexanes:methylene chloride 9:1). ${ }^{1} \mathrm{H}$ NMR $\left(\mathrm{CDCl}_{3}\right) \square 1.19(\mathrm{~d}, 36 \mathrm{H}, J=7.2 \mathrm{~Hz}), 1.43$ (septet, $6 \mathrm{H}, J=7.2$ $\mathrm{Hz}), 4.24(\mathrm{~s}, 6 \mathrm{H}), 7.28(\mathrm{~d}, 2 \mathrm{H}, J=8 \mathrm{~Hz}), 7.51(\mathrm{dd}, 2 \mathrm{H}, J=3.2,6.8 \mathrm{~Hz}), 7.62(\mathrm{~d}, 2 \mathrm{H} J=$ $3.2 \mathrm{~Hz}$ ), $7.64(\mathrm{dd}, 2 \mathrm{H}, J=3.2,6.8 \mathrm{~Hz}), 8.40(\mathrm{dd}, 2 \mathrm{H}, J=2.8,6.4 \mathrm{~Hz}), 8.84(\mathrm{dd}, 2 \mathrm{H}, J=$ $3.2,6.8 \mathrm{~Hz}) .{ }^{13} \mathrm{C} \mathrm{NMR}\left(\mathrm{CDCl}_{3}\right) \square 12.06,18.81,64.16,96.44,96.65,115.22,123.29$, 124.70, 125.77, 126.27, 127.37, 127.52, 129.42, 132.80, 133.11, 136.01, 138.75, 149.89. MS (m/z, EI) $813(50 \%, \mathrm{M}+), 786(50 \%, \mathrm{M}+-2 \mathrm{Me})$. Anal Calcd for $\mathrm{C}_{50} \mathrm{H}_{60} \mathrm{~S}_{2} \mathrm{Si}_{2} \mathrm{O}_{4}$ (endoperoxide formed during shipment): $\mathrm{C}, 71.04 ; \mathrm{H}, 7.15$. Found $\mathrm{C}, 71.51 ; \mathrm{H}, 7.39$. Melting point: $164{ }^{\circ} \mathrm{C}$. Fluorescence Quantum Efficiency: 0.36. Yield: $17 \%$. UV-Vis 
(hexanes) $\square_{\mathrm{nm}}(\log \square$ : 303 (4.65), 389 (4.32), 412 (4.15), 532 (3.25), 571 (3.74), 617 (3.89).

Fabrication of OLEDs

ITO glass was provided by Gentex Corporation. The ITO glass was patterned by using a shadow mask to spray lacquer onto the ITO glass, then removing the exposed ITO using an aqua regia bath (10:10:1:: $\mathrm{H}_{2} \mathrm{O}: \mathrm{HCl}: \mathrm{HNO}_{3}, 20 \mathrm{~min}$.). The lacquer was removed with acetone. The remaining ITO was treated with sonication in a dilute aqua regia bath $\left(2: 7: 25:: \mathrm{HNO}_{3}: \mathrm{HCl}: \mathrm{H}_{2} \mathrm{O}\right)$ until the ITO turned from red-violet to blue-gold (approx. $20 \mathrm{~min}$.). The ITO glass was treated with an RCA bath (1:1:5:: $\mathrm{H}_{2} \mathrm{O}_{2}: \mathrm{NH}_{4} \mathrm{OH}: \mathrm{H}_{2} \mathrm{O}, 30 \mathrm{~min}$.). The substrates were washed with sonication in water (5 min.), isopropanol (5 min.), and acetone (5 min.) after which they were dried under nitrogen. The substrates were further dried in an oven $\left(110^{\circ} \mathrm{C}, 15 \mathrm{~min}\right.$.).

Following the substrate preparation, layers of compounds were deposited via evaporation under a vacuum of $10^{-5} \mathrm{mbar}$. The layers used were the hole-transporting layer (TPD, $40 \mathrm{~nm}$ ), the light-emitting layer (tetracene derivative, $30 \mathrm{~nm}$ ), a buffer layer (LiF, $0.8 \mathrm{~nm}$ ), and the cathode (aluminum, $60-100 \mathrm{~nm}$ ). Current and luminance data were recorded for the OLEDs. Examples of the voltage-current-luminance data are shown below.

Current, Voltage, Luminance Data for OLED with Compound 3:

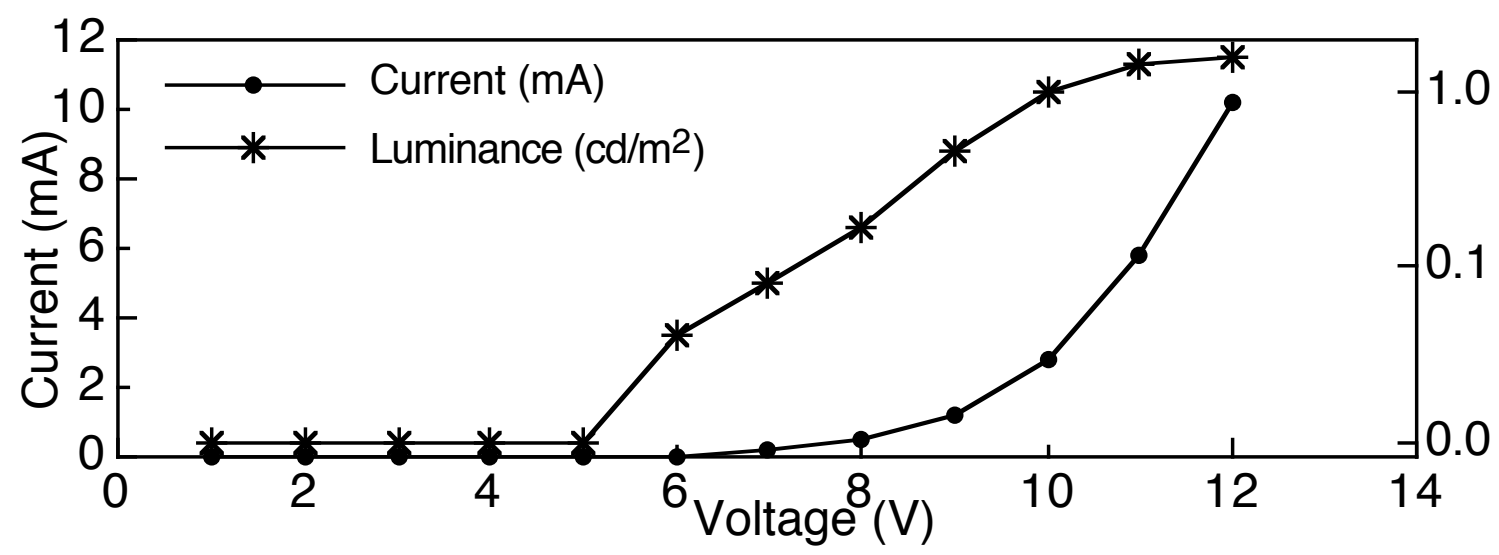

Current, Voltage, Luminance Data for OLED with Compound 7: 


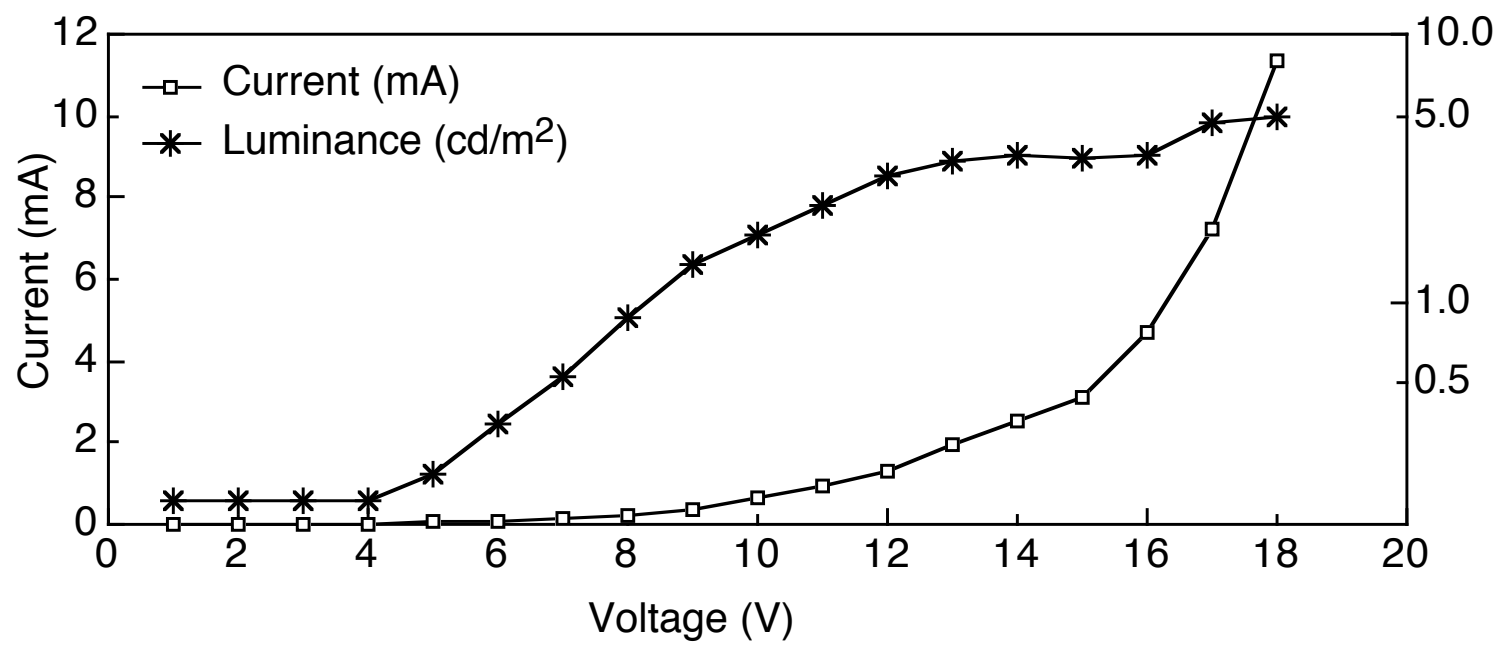

References:

1. Fery-Forgues, S.; Lavabre, D. J. Chem. Ed. 199, 76, 1260.

2. Hanhela, P. J.; Paul, D. B. Aust. J. Chem. 1981, 34, 1701.

3. Khanapure, S. P.; Reddy, R. T.; Biehl, E. R. J. Org. Chem. 1987, $52,5685$. 
Compound 3

${ }^{1} \mathrm{H}$ NMR

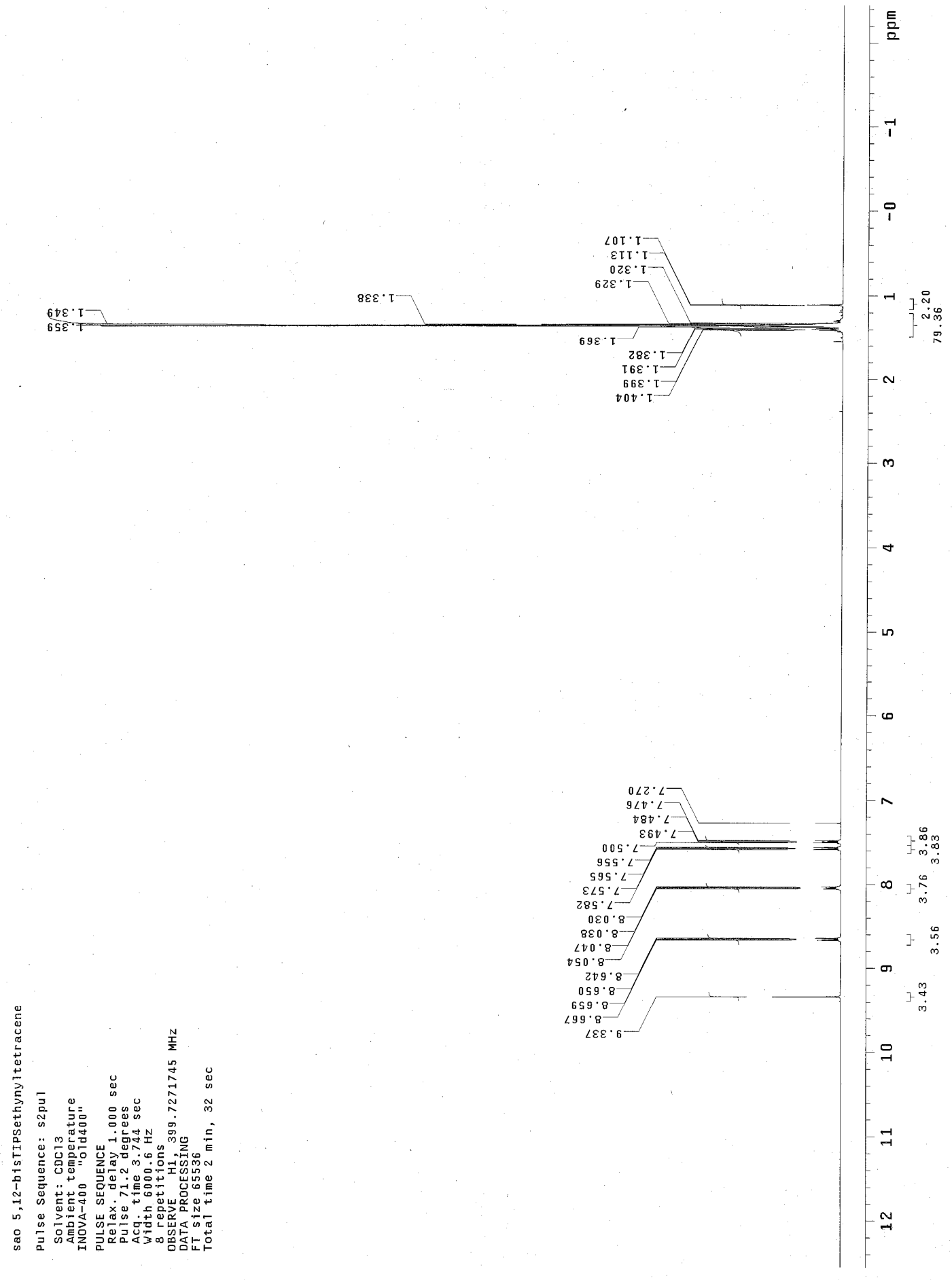


Compound 3

${ }^{13} \mathrm{C}$ NMR

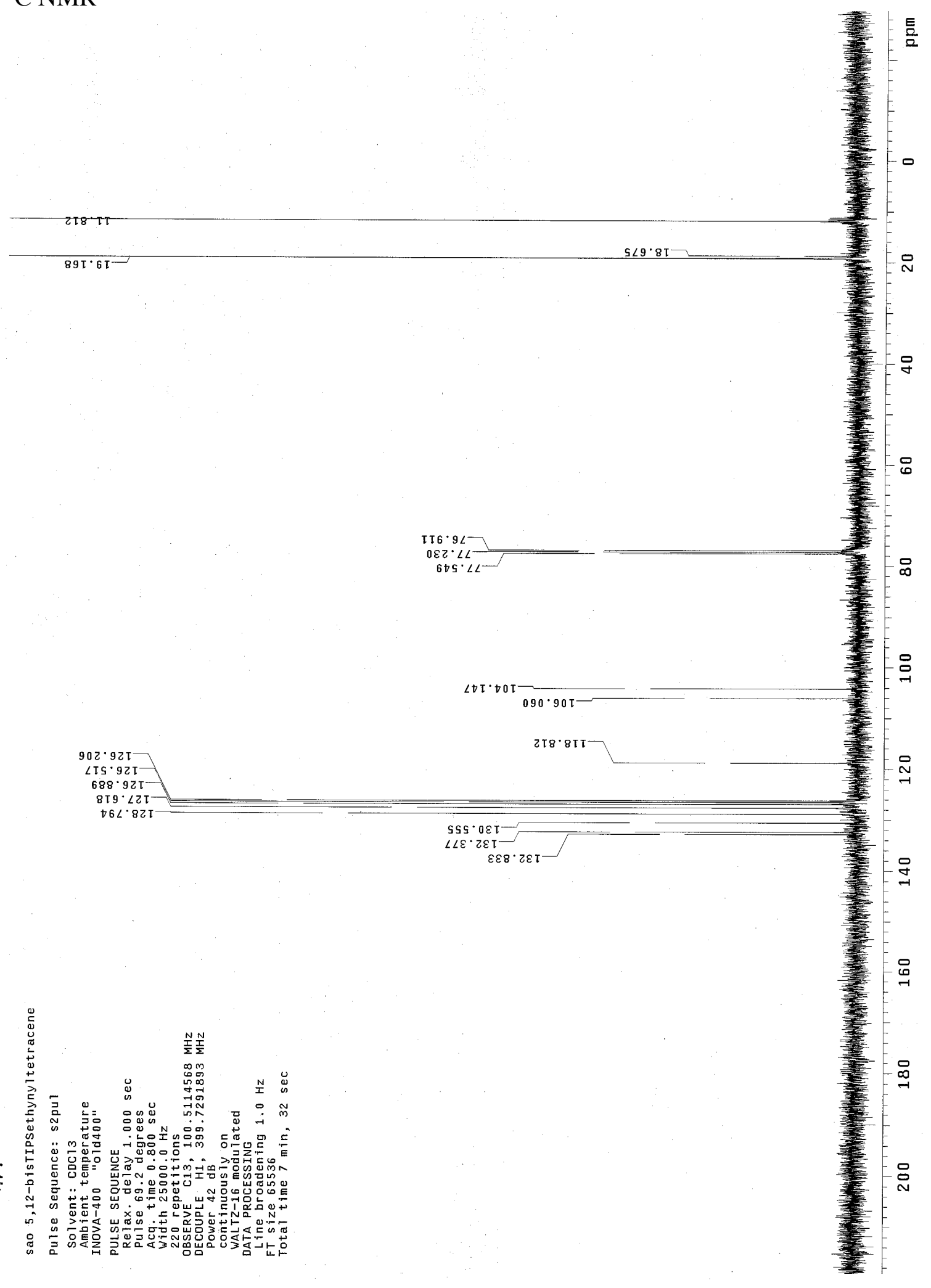


Compound 4

${ }^{1} \mathrm{H}$ NMR

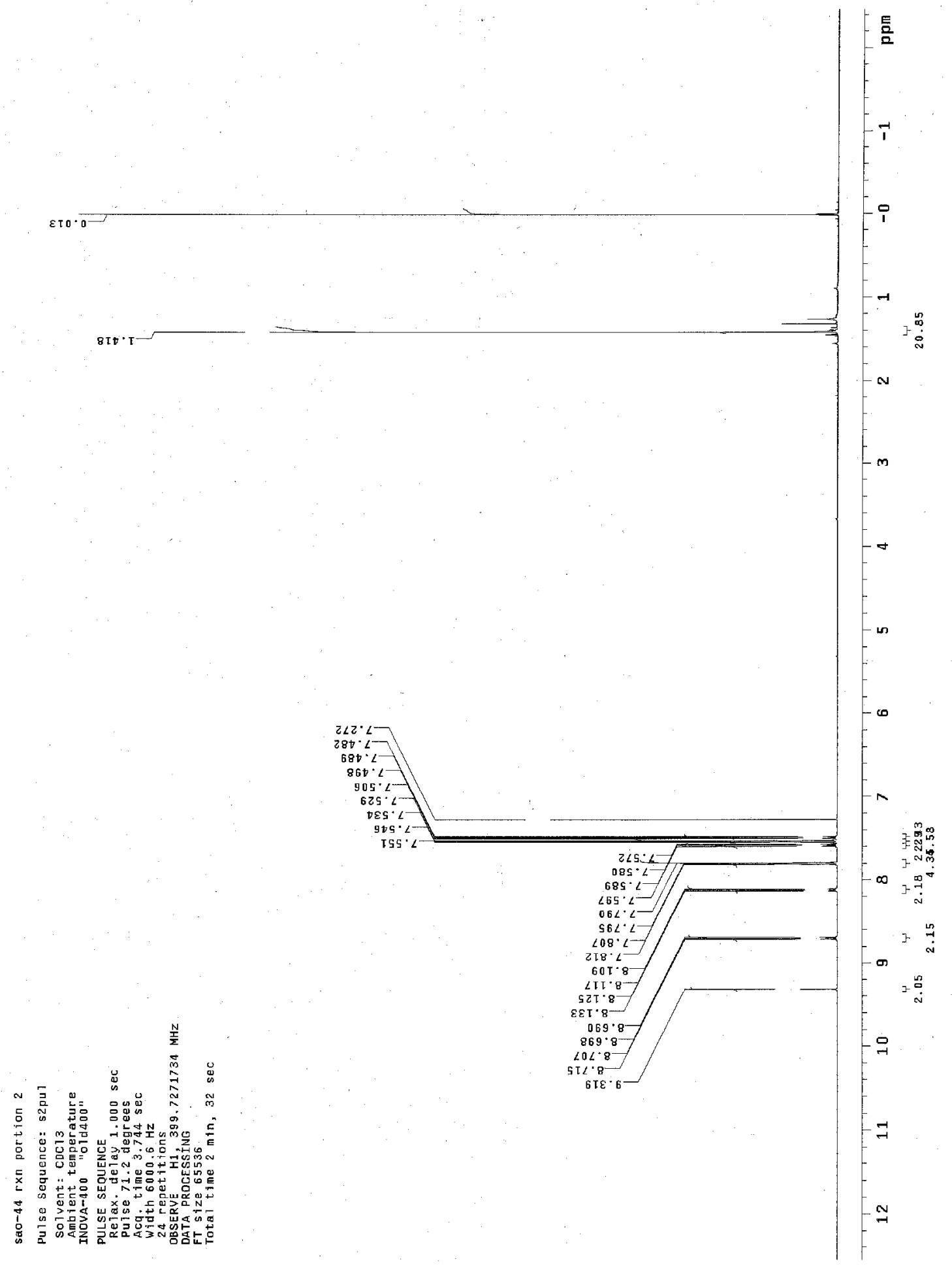


Compound 4

${ }^{13} \mathrm{C}$ NMR

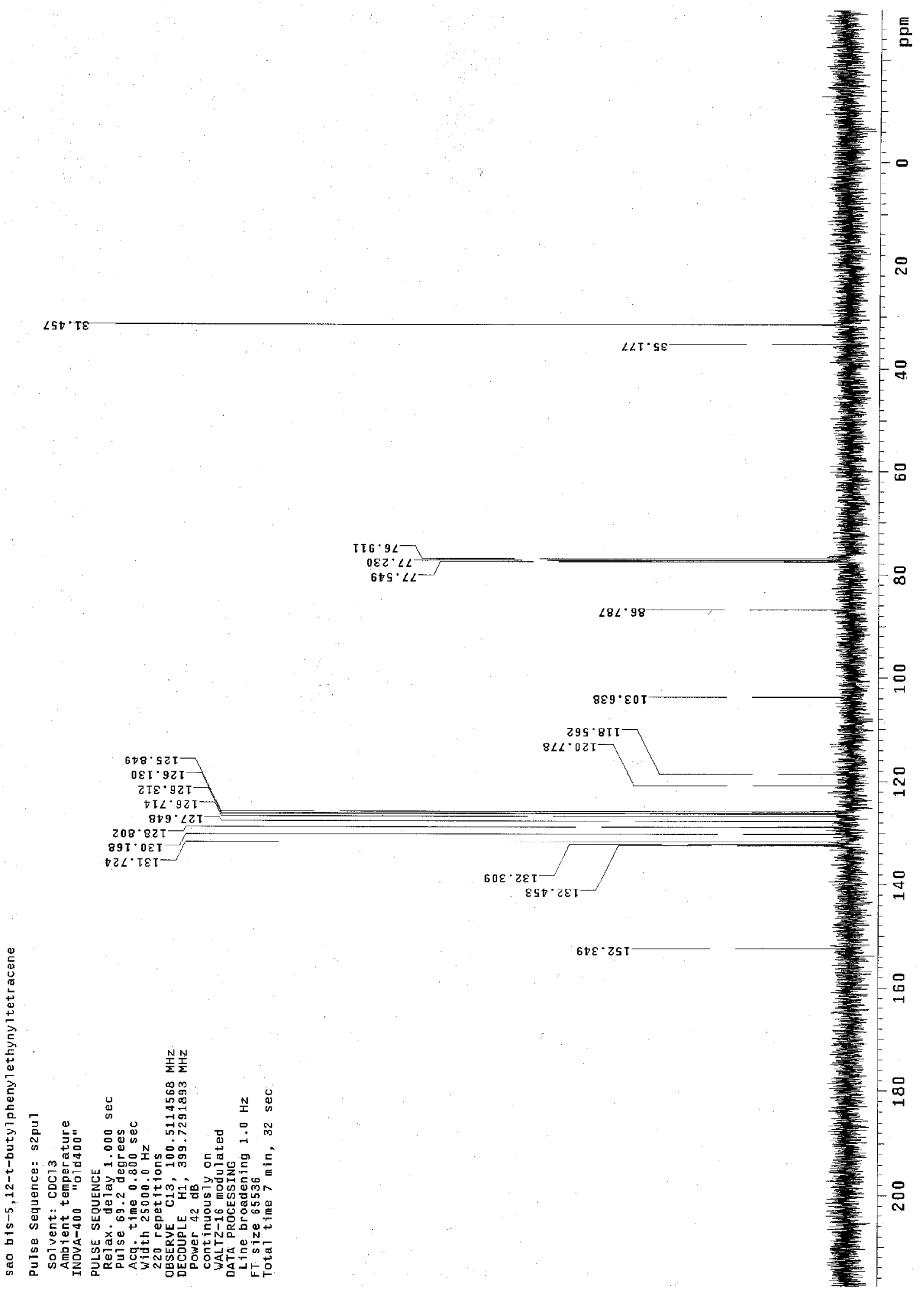


Compound 5

${ }^{1} \mathrm{H}$ NMR

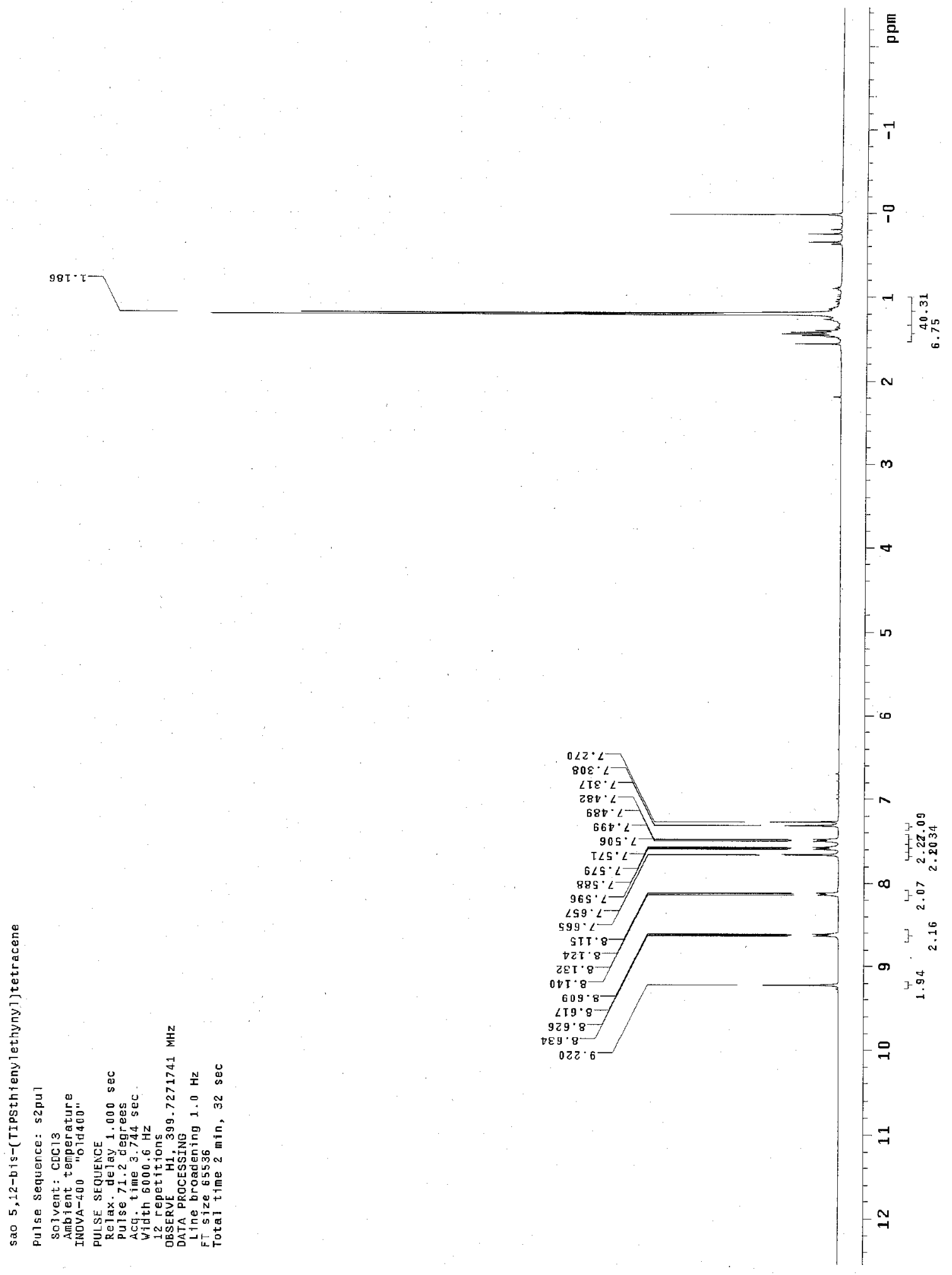


Compound 5

${ }^{13} \mathrm{C}$ NMR

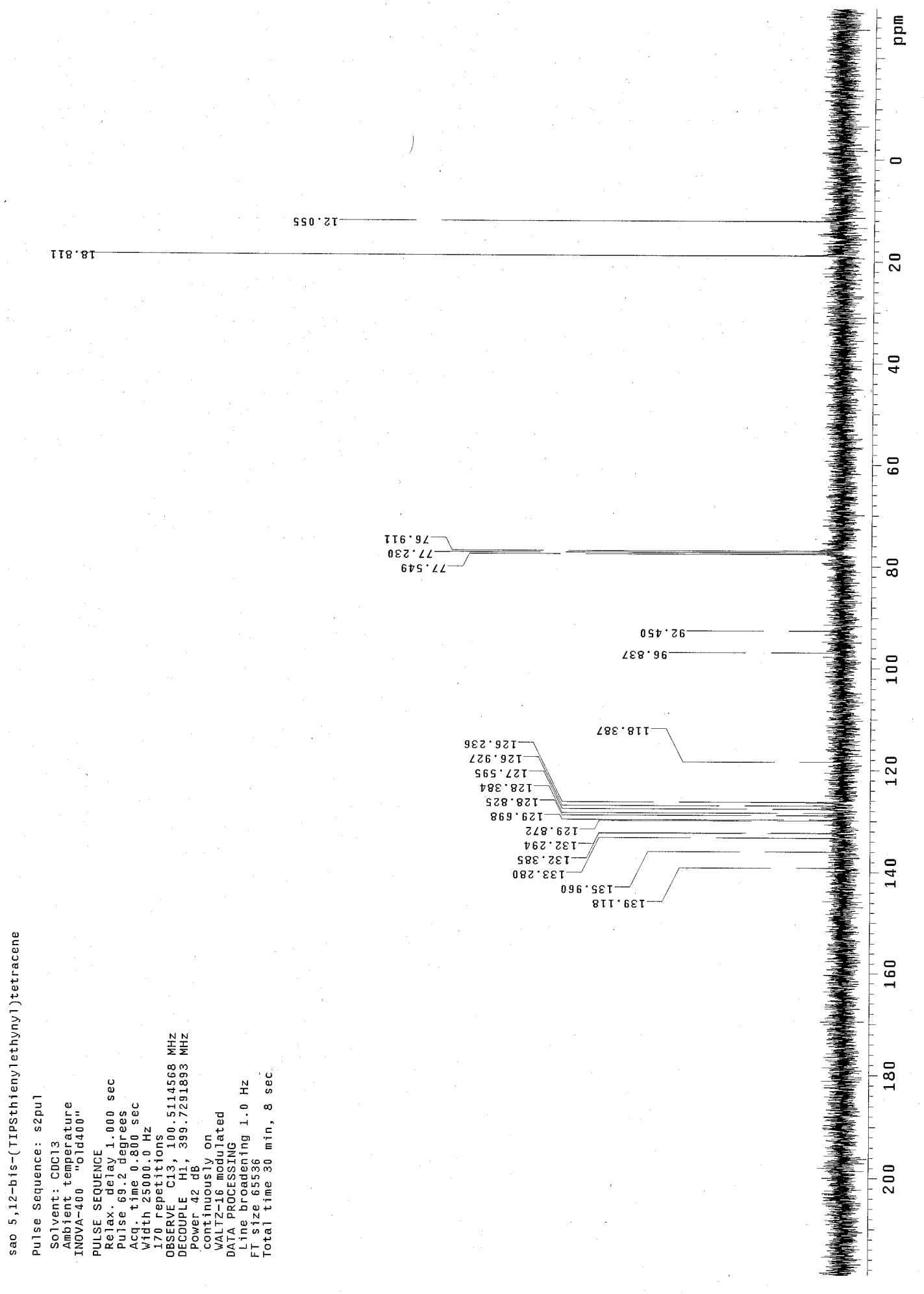


Compound 6

${ }^{1} \mathrm{H}$ NMR

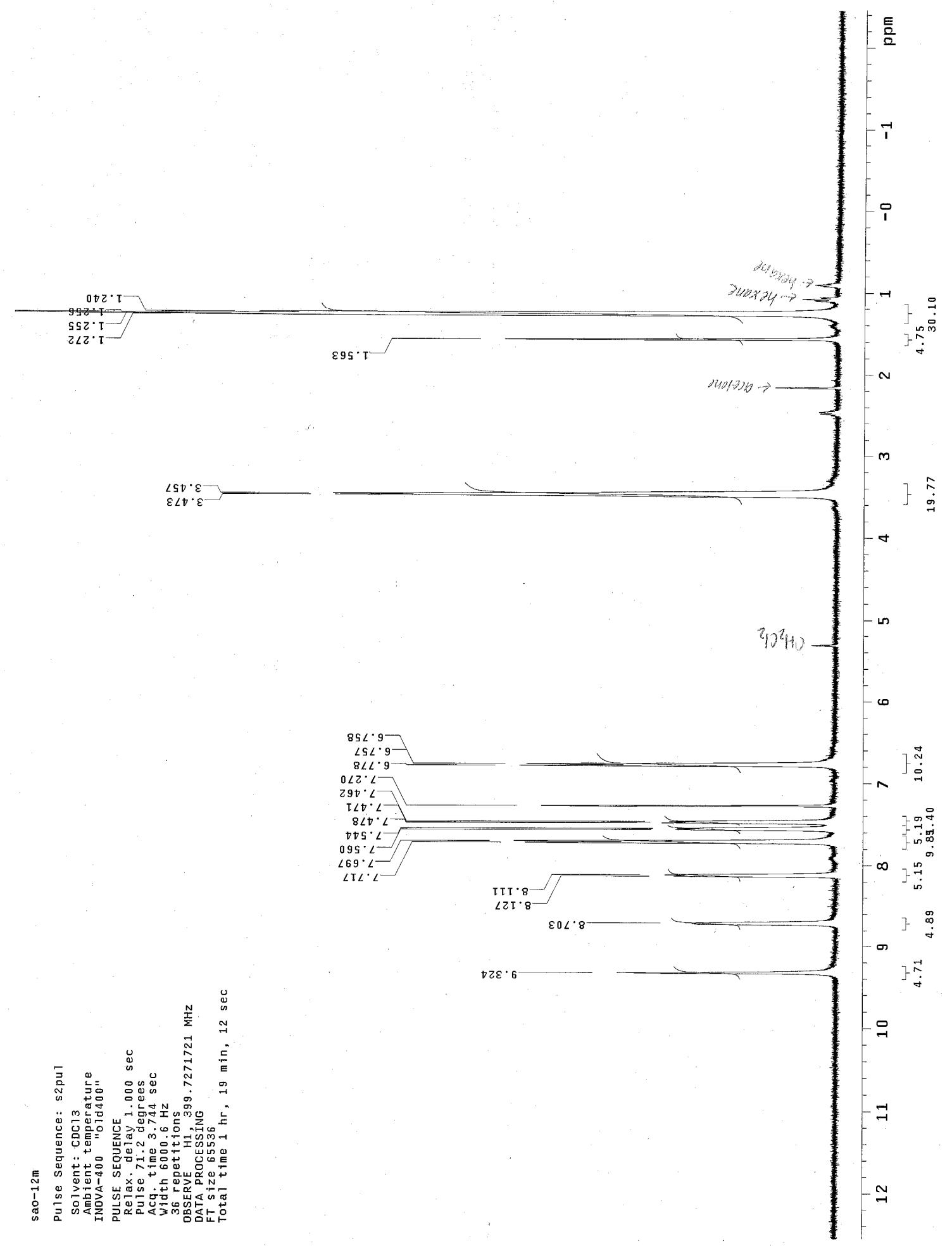


Compound 6

${ }^{13} \mathrm{C}$ NMR

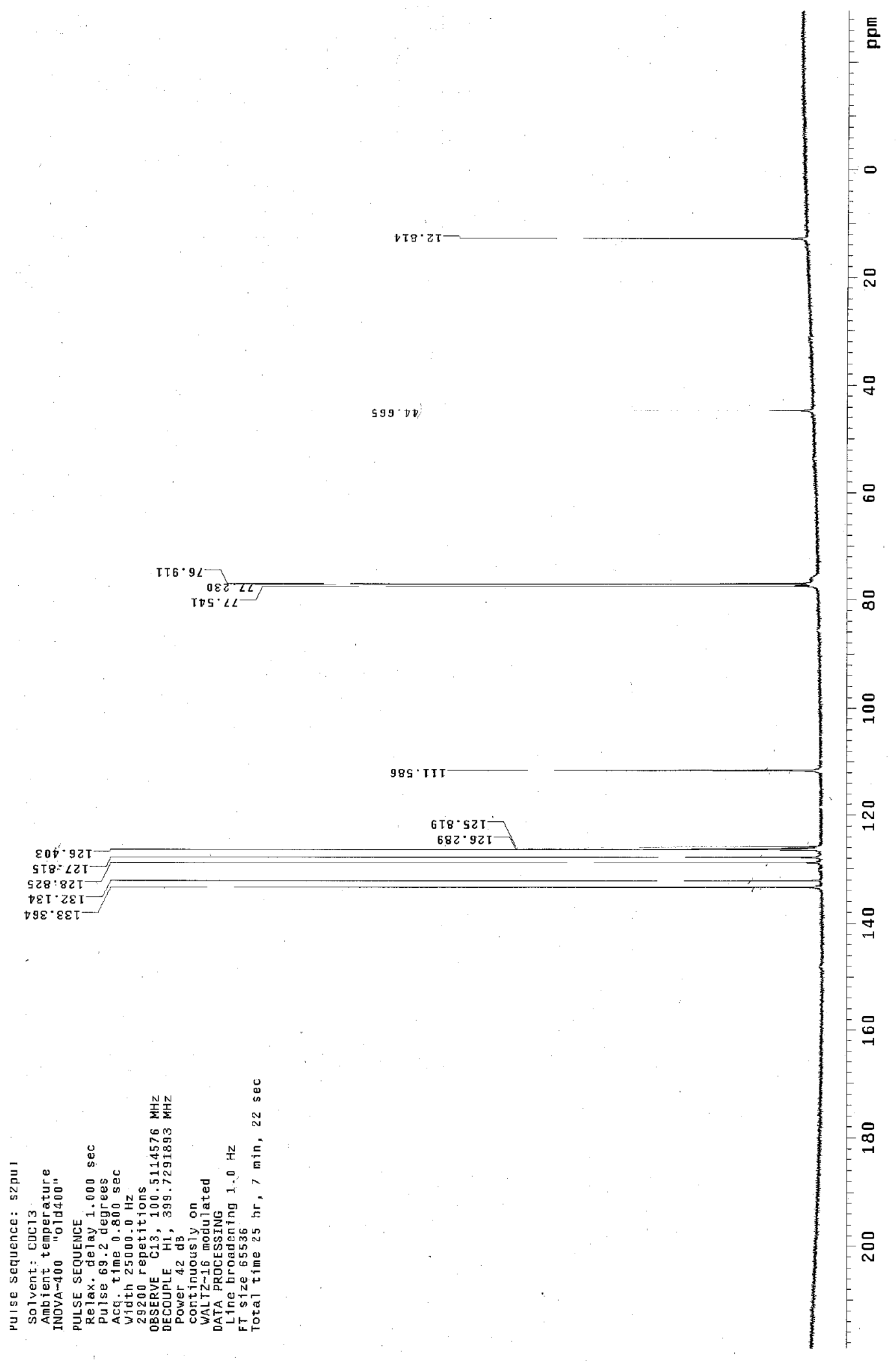


Compound 7

${ }^{1} \mathrm{H}$ NMR

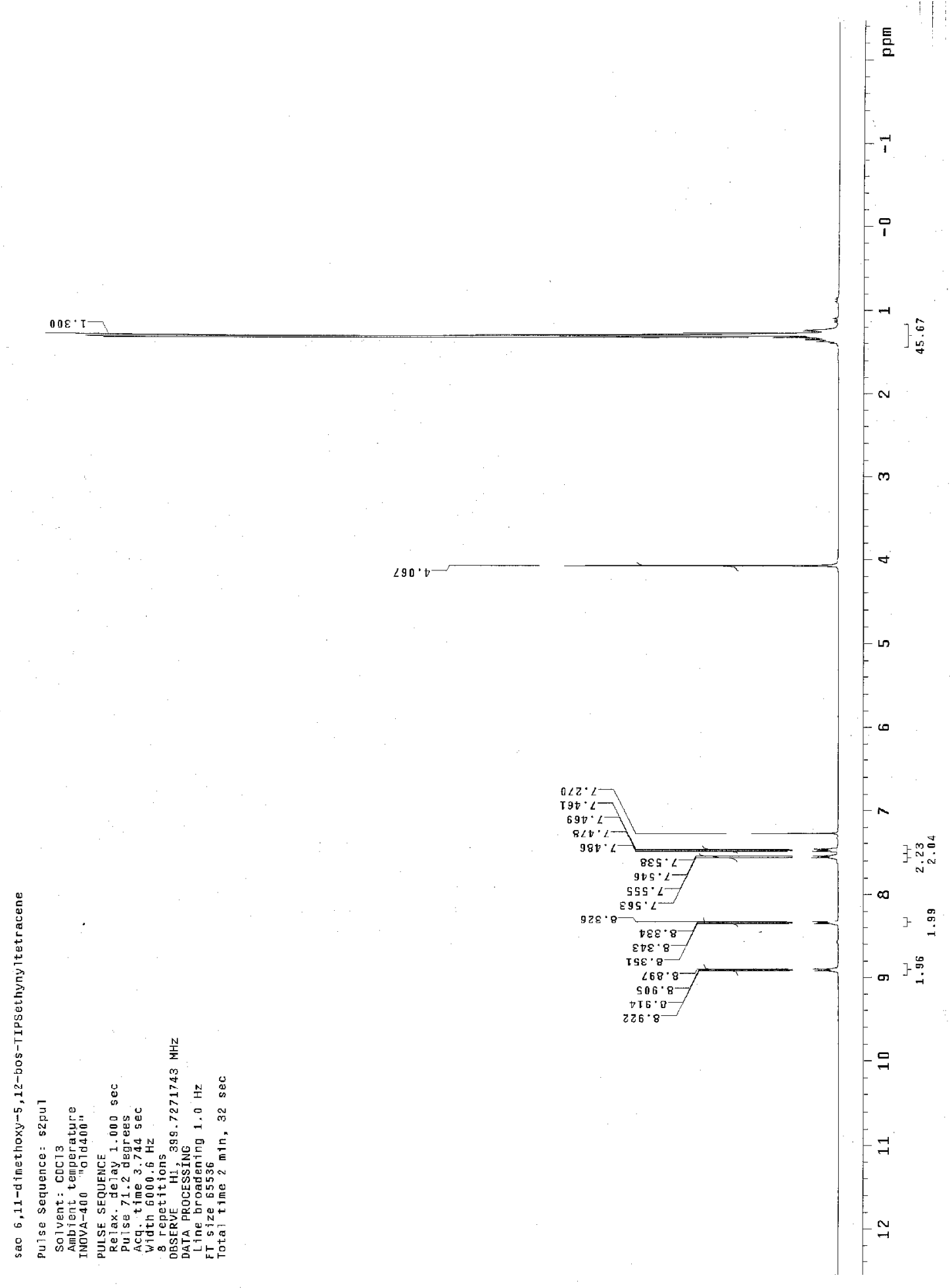


Compound 7

${ }^{13} \mathrm{C}$ NMR

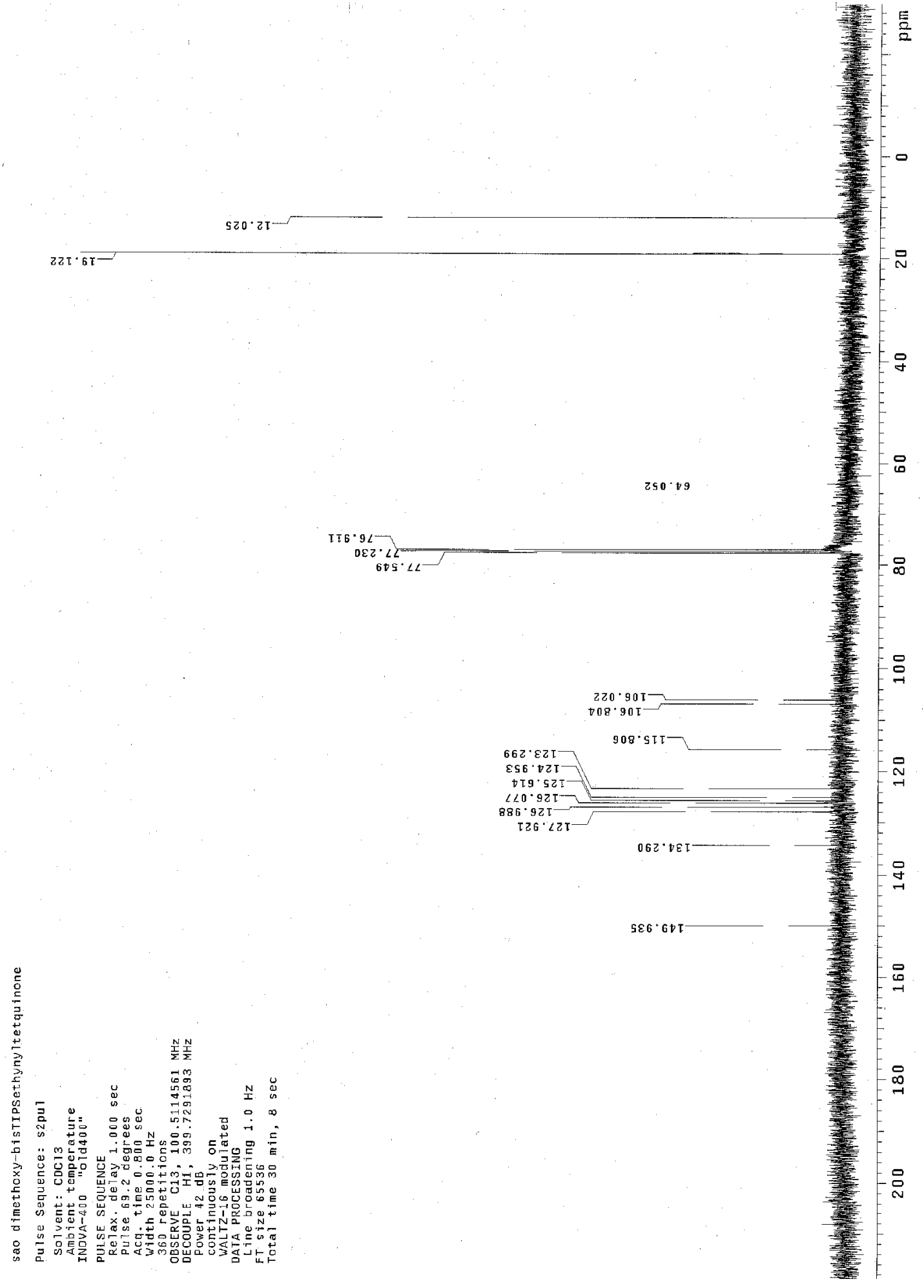


Compound 8

${ }^{1} \mathrm{H}$ NMR

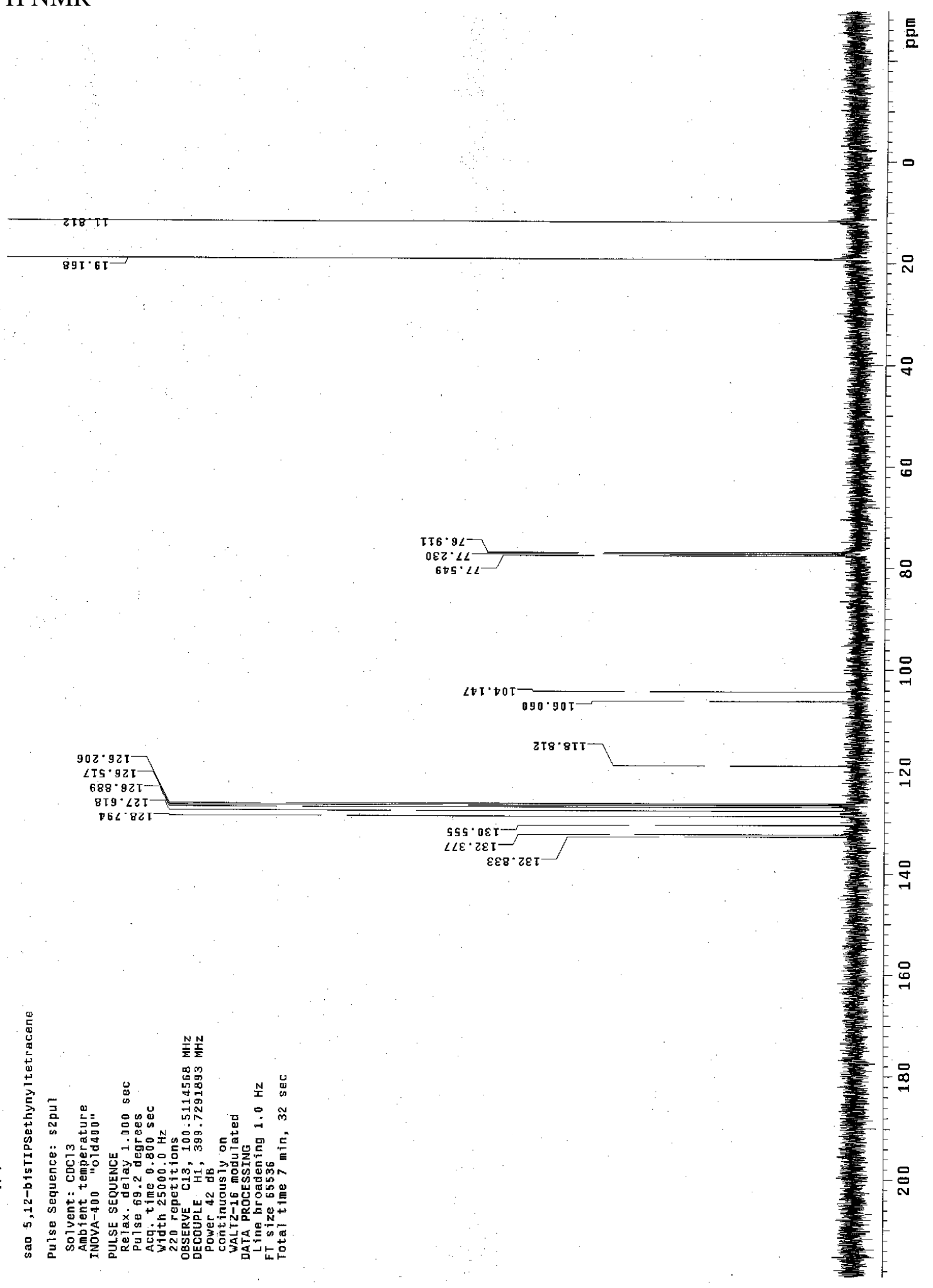


Compound 8

${ }^{13} \mathrm{C}$ NMR

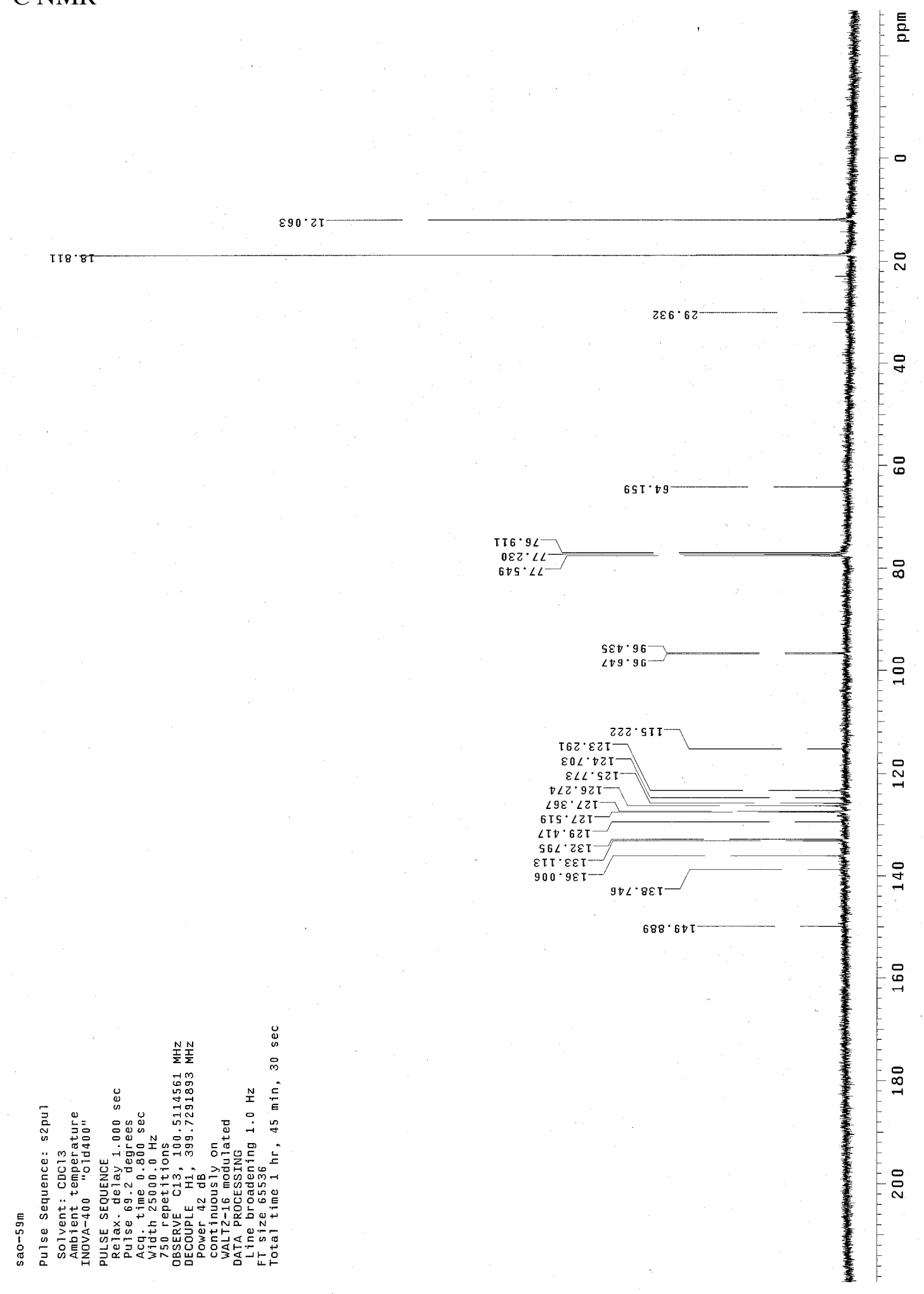

